\title{
ANALISIS EKUITAS MEREK BERBASIS PELANGGAN \\ PADA MINIMARKET INDOMARET \\ DI SALATIGA
}

\author{
Oleh \\ Dody Ariyadi \\ Alumni STIE AMA Salatiga \\ Yanuar Surya Putra \\ Dosen STIE AMA Salatiga
}

\begin{abstract}
Retail Business is of the biggest inustry in Indonesia and already seemed to be a broad people's lifestyles. Indomaret is one of a retail franchise network in Indonesia. Consumer shopping behavior is formed because the value of a brand that increases a sense of pride. The purpose of this study was to examine the analysis of brand equity based customers for Indomaret, conducted to determine the level of Brand Salience, Brand Performance, Brand Imagery, Brand judgments, Brand Feelings and Brand Resonance of Indomaret, so the company can find a clear overview of Indomaret brand in the public eye, especially customers. The number of samples in this study were 200 samples, which ever shopped at Indomaret in Salatiga. The analysis tool used is the chi-square.

Overall consumers know the brand equity of Indomaret seen from the chi-square test salience 2268.244, 1515.336 performance, imagery 1918.372, 5245.927 judgments, feelings 3368.959, 1660.247 and its resonance with the values $232.912 \chi^{2}$ tabel so Ha is significant and responded positively. It can be concluded that the respondents already know, learn, see, feel, and has experience with a mini Indomaret all the time, so that the company already provides for the obligations and assets owned by a brand.
\end{abstract}

Keywords: Ekuitas merek, Brand Salience, Brand Performance, Brand Imagery,Brand Judgments, Brand Feelings, Brand Resonance 


\section{A. PENDAhuluan}

Menurut American Marketing Association, dikutip dalam buku The Power of Brands karangan Freddy Rangkuti (2002 : 7) definisi merek sebagai berikut Merek adalah nama, istilah, tanda, simbol atau rancangan atau kombinasi dari hal- hal tersebut. Tujuan pemberian merek adalah untuk mengidentifikasi produk atau jasa yang dihasilkan sehingga berbeda dari produk atau jasa yang dihasilkan oleh para pesaing.

Merek harus memiliki kualitas yang lebih sehingga suatu merek dapat dikenal dan memiliki keunikan sendiri, merek adalah sesuatu yang dibeli konsumen. Konsumen biasanya tidak menjalin relasi dengan barang atau jasa tertentu, namun sebaliknya membina hubungan yang kuat dengan merek spesifik. Merek haruslah mengandung aset dan kewajiban yang menambah atau mengurangi nilai yang diberikan sebuah produk atau jasa kepada perusahaan atau pelanggan perusahaan tersebut yang didefinisikan sebagai ekuitas merek. Menurut Kotler dan Amstrong (2003:350) ekuitas merek merupakan nilai suatu merek berdasarkan seberapa kuat nilai merek tersebut memilki nilai loyalitas merek, kesadaran konsumen akan merek tersebut, kualitas yang dipersepsikan, asosiasi merek, dan berbagai aset lainnya seperti paten, merek dagang dan hubungan jaringan distribusi.

Sejalan dengan perkembangan yang berlangsung di Indonesia saat ini dari tahun ke tahun proses pemenuhan kebutuhan hidup terutama yang menyangkut mengenai kebutuhan primer serta sekunder yang terus meningkat. Hal ini menyebabkan manusia yang berperan sebagai konsumen menginginkan proses pembelian barang-barang kebutuhan sehari-hari agar tercipta lebih muda, dimana pada saat ini kita semua mengenalnya sebagai sebuah tempat belanja yang mudah dan langsung. Hal ini mendorong para pengusaha menanamkan modalnya dibidang usaha retail serta mem-perluasnya. Bisnis ritel di Indonesia telah menyebar ke hampir seluruh pelosok negeri, mulai dari ritel berskala kecil seperti kios-kios, warung, pedagang kaki lima, dll. hingga perusahaan-perusahaan ritel berskala besar seperti specialty store, department store, super market, dan lain-lain. Dari hal tersebut tentunya akan memengaruhi pertumbuhan ekonomi masyarakat di daerahnya masing-masing yang mendapatkan dampak dari hadirnya ritel yang telah menjamur di seluruh Indonesia. Berdasarkan paparan Direktur Jenderal Perdagangan Dalam Negeri Kementerian Perdagangan, Srie Agustina di Kantor Kementerian Perdagangan (Kemendag), Jakarta Pusat, Kamis tanggal 30 Januari 2014 yang dimuat pada bisnis.liputan6.com dijelaskan bahwa pertumbuhan gerai tersebut di dominasi oleh ritel tradisional sebanyak 750 ribu gerai atau tumbuh sebesar $42 \%$ dan ritel modern dalam format mini market dengan pertumbuhan sebanyak 16 ribu gerai atau tumbuh sebesar $400 \%$.dengan munculnya usaha-usaha retail baru tersebut tentu 
dapat mempengaruhi pasang pasar yang sudah ada. Untuk itu maka perlu adanya peningkatan pelayanan yang tepat agar konsumen yang telah dikuasai dapat dipertahankan atau bisa meningkatkan konsumen yang sudah ada tersebut, dengan adanya hal tersebut ternyata dapat dihadirkan oleh para pelaku bisnis usaha retail yang menempatkan. Usaha-usaha retail tersebut telah kita kenal dengan sebutan minimarket dalam skala kecil. Indomaret adalah jaringan peritel waralaba di Indonesia. Indomaret merupakan salah satu anak perusahaan Salim Group. Indomaret merupakan jaringan minimarket yang menyediakan kebutuhan pokok dan kebutuhan sehari-hari. Dikelola oleh PT. Indomarco Prismatama, cikal bakal pembukaan Indomaret di Kalimantan dan toko pertama dibuka di Ancol, Jakarta Utara, pada tahun 1988.

Oleh karena itu analisis terhadap ekuitas merek berbasis pelanggan atas Minimarket Indomaret, dilakukan untuk mengetahui tingkat brand salience, brand performance, Brand imagery, Brand judgements, brand feelings dan brand resonance dari Minimarket Indomaret, dengan begitu maka perusahaan dapat mengetahui gambaran jelas mengenai brand Indomaret di mata masyarakat khususnya pelanggan. Hasil analisis ini juga diharapkan dapat memberikan manfaat bagi pihak-pihak yang terlibat dalam proses analisis ini. Berdasarkan latar belakang tersebut, maka penelitian ini akan mengangkat topic Analisis Ekuitas Merek Berbasis Pelanggan Pada minimarket Indomaret di Salatiga

\section{B. RUMUSAN MASALAH}

Berdasarkan Latar Belakang Masalah yang telah di uraikan di atas, maka penulis merumuskan masalah sebagai pokok bahasan sebagai berikut :

1. Bagaimana tingkat brand salience minimarket Indomaret di Salatiga?

2. Bagaimana tingkat brand performance minimarket Indomaret di Salatiga?

3. Bagaimana tingkat brand imagery minimarket Indomaret di Salatiga?

4. Bagaimana tingkat brand judgements minimarket Indomaret di Salatiga?

5. Bagaimana tingkat brand feelings minimarket Indomaret di Salatiga?

6. Bagaimana tingkat brand resonance minimarket Indomaret di Salatiga?

7. Bagaimana Ekuitas merek minimarket Indomaret menurut konsumen di Salatiga?

\section{PAPARAN TEORITIS}

\section{a. Ekuitas Merek}

Seperti halnya konsep merek, terdapat banyak makna konsep ekuitas merek, akuntan cenderung mendefinisikan ekuitas merek secara berbeda dengan pemasar, dimana konsep ekuitas merek dirumuskan berdasarkan relasi antara pelanggan dan merek atau sebagai sesuatu yang diperoleh pemilik merek. Dalam perspektif finansial, whitwell (Tjipono, 2005:39) yang menyatakan bahwa ekuitas merek adalah Net Present Value (NPV) dari aliran kas masa datang yang 
dihasilkan oleh suatu merek, dengan kata lain brand equty dihitung berdasarkan nilai inkremental diatas nilai yang diperoleh produk tanpa merek.

Ditinjau dari perspektif pemasaran, ekuitas merek dirumuskan sebagai nilai tambah yang dimiliki sebuah produk. Hal yang sama juga diungkapkan oleh Erdem \& Swait (dalam Fandi Tjiptono 2005:39) bahwa ekuitas merek merupakan nilai sebuah produk yang terkirim kepada konsumen. Menurut Kotler dan Amstrong (2003:350) ekuitas merek merupakan nilai suatu merek berdasarkan seberapa kuat nilai merek tersebut memilki nilai loyalitas merek, kesadaran konsumen akan merek tersebut, kualitas yang dipersepsikan, asosiasi merek, dan berbagai aset lainnya seperti paten, merek dagang dan hubungan jaringan distribusi. David A. Aaker (dalam Andi M. Shadat; 2009:163) memberikan pengertian bahwa ekuitas merek adalah serangkaian aset dan kewajiban yang terkait dengan sebuah merek, nama, dan symbol yang menambah atau nilai yang diberikan sebuah produk atau jasa kepada perusahaan dan atau pelanggan.

Beradasarkan uraian diatas dapat disimpulkan bahwa ekuitas merek merupakan nilai tambah yang dimiliki oleh sebuah merek dari sebuah produk yang diterima oleh konsumen yang dapat menimbulkan perasaan tertentu dalam pribadi konsumen. Ekuitas merek yang bernilai positif di benak pelanggan dapat meningkatkan loyalitas pelanggan terhadap suatu merek produk tertentu, sebaliknya ekuitas merek yang bernilai negatif dapat mengurangi loyalitas pelanggan.

Ekuitas merek juga bisa mempengaruhi rasa percaya diri konsumen dalam mengambil kepastian pembelian, yang lebih penting adalah kenyataan bahwa kesan kualitas dan asosiasi merek bisa menguatkan keputusan konsumen dengan pengalaman menggunakannya.

Berdasarkan perspektif ini, merek dipandang sebagai node dalam memori yang berkaitan dengan berbagai asosiasi yang berbeda dan dengan kekuatan yang bervariasi. Konsumen memahami merek sebagai kategori yang sepanjang waktu diasosiasikan dengan atribut-atribut spesifik, dimana sebagian diantaranya didasarkan pada atribut- atribut diasosiasikan dengan produk yang mewakili anggota individual kategori merek. Sejauh ini terdapat dua model ekuitas merek mapan dalam aliran psikologi konitif, yaitu model Aaker dan Keller.

Dalam model Aaker, ekuitas merek diformulasikan dari sudut pandang manajerial dan strategi korporat, meskipun landasan utamanya adalah prilaku konsumen. Aaker menjabarkan aset merek yang berkontribusi pada penciptaan ekuitas merek kedalam lima dimensi, yaitu kesadaran merek, brand quality, asosiasi merek, loyalitas merek, dan aset properitas merek lainya (Tjiptono, 2005:40)

1) Kesadaran merek

Kesadaran merek, yaitu kemampuan konsumen untuk mengenali atau mengingat bahwa sebuah merek merupakan anggota dari kategori produk tertentu (Durianto, Sugiarto, Sitinjak 2001:4). Peran kesadaran merek terhadap ekuitas merek dapat dipahami dengan membahas bagaimana 
kesadaran merek menciptakan suatu nilai. Penciptaan nilai dapat dilakukan dengan empat cara :

a) Anchor to which other association can be attached, artinya suatu merek dapat digambarkan dengan suatu jangkar dengan beberapa rantai. Rantai menggambarkan asosiasi tersebut.

b) Familiarity-Lingking, artinya dengan mengenal merek akan menimbulkan rasa terbiasa terutama untuk produk-produk yang bersifat keterlibatan rentah.

c) Substance/Commitment, Kesadaran akan menandakan keberadaan, komitmen, dan inti yang sangat penting bagi suatu perusahaan.

d) Brand to Consider, Langkah pertama dalam melakukan suatu proses pembelian adalah menyeleksi dari suatu kelompok merek-merek yang dikenal untuk dipertimbangkan merek mana yang akan diputuskan dibeli. Pengukuran kesadaran merek didasarkan pada pengertian-pengertian pengenalan merek yang mencakup tingkatan kesadaran merek (Durianto, sugiarto, Sitinjak, 2001:4), yaitu puncak pikiran, pengingatan kembali merek, pengenalan merek dan tidak mengenal merek.

\section{2) Brand quality}

Brand quality, merupakan penilaian konsumen terhadap keunggulan atau superioritas produk secara keseluruhan. Oleh sebab itu brand quality didasarkan evaluasi subyektif konsumen terhadap kualitas produk (Durianto, Sugiarto, Sitinjak, 2001:69).

Menurut pendapat Garvin yang dikutip oleh Durianto, Sugiarto, Sitinjak (2001:71), dimensi percieved quality dibagi menjadi 7 : Kinerja pelayanan, ketahanan, keandalan, karakteristik produk, kesesuaian dengan spesifikasi, dan hasil.

3) Asosiasi merek

Asosiasi merek, yakni segala sesuatu yang terkait dengan memori terhadap sebuah merek, berkaitan erat dengan brand image, yang didefinisikan asosiasi merek dengan makna tertentu (Durianto, Sugiarto, Sitinjak, 2001:69). Asosiasi merek memiliki tingkat kekuatan tertentu dan akan semakin kuat seiring dengan bertambahnya pengalaman konsumsi. Asosiasi-asosiasi yang terkait dengan suatu merek umumnya dihubungkan dengan berbagai hal berikut: atribut produk, atribut tak berwujud, manfaat bagi pelanggan, harga relatif penggunaan / aplikasi pengguna, orang terkenal, gaya hidup, kelas produk para pesaing, negara/wilayah geografis.

4) Loyalitas merek

Loyalitas merek, mencerminkan tingkat keterikatan konsumen dengan suatu merek produk (Durianto, Sugiarto, Sitinjak, 2001:126). Dalam kaitannya dengan loyalitas merek dengan suatu produk, didapati adanya beberapa tingkatan loyalitas merek, yaitu switcher (berpindah-pindah), Habitual buyer (Pembeli yang bersifat kebiasaan), satisfied buyer (pembeli yang puas dengan biaya peralihan), like the brand (menyukai merek), commited buyer (pembeli yang komit) 
Sementara itu model Keller lebih berfokus pada perspektif perilaku konsumen. Ia mengembangkan model equitas merek berbasis pelanggan (CBBE : Customer-Based Ekuitas merek). Menurut Keller model ini menekankan bahwa kekuatan sebuah merek terletak apa yang dipelajari, dirasakan, dilihat dan didengarkan konsumen tentang merek tersebut sebagai hasil pengalamannya sepanjang waktu (Tjiptono, 2005:41). Berdasarkan model ini, sebuah merek dikatakan memiliki customer-based ekuitas merek positif apabila pelanggan bereaksi lebih positif terhadap sebuah produk dan cara produk tersebut dipasarkan manakala mereknya diidentifikasi, dibandingkan bila nama mereknya tidak teridentifikasi. Ekuitas merek baru terbentuk jika pelanggan mempunyai tingkat awareness dan familiaritas yang tinggi terhadap sebuah merek dan memiliki asosiasi merek yang kuat positif dan unik dalam memorinya. Keller mengajukan proses empat langkah dalam membangun merek: menyusun identitas merek yang tepat, menciptakan makna merek yang sesuai, menstimulasi respon merek yang diharapkan, dan menjalin relasi merek yang tepat bagi pelanggan. Denagn kata lain keempat langkah ini mencerminkan empat pertanyaan fundamental :

1) Who are you? (identitas merek)

2) What are you? (makna merek)

3) What about you, what do I think or feel about you ? (respon merek)

4) What about you and me ? what kind association and how much of a connection would I like to have with you? (relasi merek)

Prose implementasi keempat tahap ini membutuhkan enam building blocks utama, yaitu brand salience, brand performance, brand imagery, brand judgements, brand feelings dan brand resonance.

1) Brand salience, sangat erat kaitanya dengan konsumen, berkenaan dengan aspek-aspek awareness sebuah merek, seperti seberapa sering dan mudahkah merek diingat dan dikenali dalam berbagai situasi. Tahapannya sebagai berikut: puncak ingatan, mengingat merek, mengenal merek dan tidak mengenal merek. Semakin tinggi brand salience maka semakin tinggi tingkat konsumsi dan volume penjualan pula.

2) Brand performance, berkenaan dengan kemampuan produk dan jasa dalam memenuhi kebutuhan fungsional konsumen. Secara garis besar ada lima atribut dan manfaat pokok yang mendasari brand performance

a) Unsur primer dan fitur suplemen

b) Reliabilitas, durabilitas, dan serviceability produk

c) Efektivitas, efisiensi, dan empati layanan

d) Model dan desain

e) Harga

Pada hakikatnya, brand performance mencerminkan intrinsic properties merek dalam hal karakteristik inheren sebuah produk atau jasa.

Brand performance adalah jantung dari brand image, Ini merupakan pengaruh utama dari pengalaman konsumen, apa yang mereka dengar, apa yang produsen kemukakan mengenahi merek. Brand performance adalah 
cara sebuah produk atau jasa berusaha untuk memenuhi kebutuhan konsumen lebih akan kebutuhan fungsional produk atau jasa.

3) Brand imagery, menyangkut extrinsic properties produk atau jasa, yaitu kemampuan merek dalam memenuhi kebutuhan psikologis atau social atau pelanggan. Brand imagery bisa terbentuk secara langsung dan tak langsung. Empat kategori brand imagery meliputi :

a) Profil pemakai

b) Situasi pembelian dan pemakian

c) Kepribadian dan nilai-nilai

d) Sejarah, warisan, dan pengalaman

Brand image atau brand description, yakni deskripsi tentang asosiasi dan keyakinan konsumen terhadap merek tertentu. Menurut Kotler, dalam Armstrong(2001:225) "Brand image adalah keyakinan tentang merek tertentu". Citra atau asosiasi merepresentasikan persepsi yang bisa merefleksikan kenyataan yang objektif ataupun tidak. Citra yang terbentuk dari asosiasi inilah yang mendasari dari keputusan membeli bahkan loyalitas merek (brand loyalty) dari konsumen. Citra merek adalah apa yang konsumen pikirkan dan rasakan ketika mendengar atau melihat nama suatu merek menurut Setiadi (2003:180).

4) Brand judgements, berfokus pada pendapat dan evaluasi personal konsumen terhadap merek dan asosiasi citra yang dipersepsikannya.

Aspek brand judgements meliputi :

a) Brand quality, yakni persepsi konsumen terhadap nilai dan kepuasannyang dirasakannya.

b) Brand credibility, yaitu seberapa jauh sebuah merek dinilai kredibel dalam hal expertise (kompeten, inovatif, pemimpin pasar), trustworthiness (bisa diandalkan, selalu mengutamakan kepentingan pelanggan), dan likeability (menarik, memang layak untuk dipilh dan digunakan).

c) Brand consideration, yaitu sejauh mana sebuah merek dipertimbangkan untuk dibeli atau digunakan oleh konsumen.

d) Brand superiority, yakni sejauh mana konsumen menilai merek bersangkutan unik dan lebih baik disbanding dengan merek-merek lain.

5) Brand feelings, yaitu tanggapan dan reaksi emosional konsumen terhadap merek. Emosi yang di timbulkan oleh merek ini, dapat menjadi begitu kuat, muncul ketika menggunakan merek.

Reaksi pelanggan yang secara emosional berkenaan dengan merek beupa:

a) Manfaat ekspresi diri, dimana ketika konsumen menggunakan suatu merek, maka akan menimbulkan perasaan lebih baik, konsumen merasa bangga, sukses dan penuh percaya diri.

b) Munculnya pengakuan sosial, yaitu ketika menggunakan sebuah merek akan menimbulkan perasaan positif bagi konsumen.

6) Brand resonance, mengacu pada karakteristik relasi yang dirasakan pelanggan terhadap merek spesifik. Resonance tercermin pada intensitas 
atau kekuatan ikatan psikologis antara pelanggan dan merek, serta tingkat aktivitas yang ditimbulkan loyalitas tersebut.

Ini adalah keadaan dimana seseorang merasa sebuah merek sudah menjadi bagian dalam kehidupanya. Hubungan ini sangat kuat bahwa anggota dari komunitas merek berkeinginan, sudi untuk membuat investasi (menanamkan uang) dari sumber daya mereka untuk tetap berhubungan dengan merek.

Berdasarkan tinjauan landasan teori dan penelitian terdahulu, maka dapat disusun kerangka pemikiran dalam penelitian ini, seperti tersaji dalam gambar berikut ini:

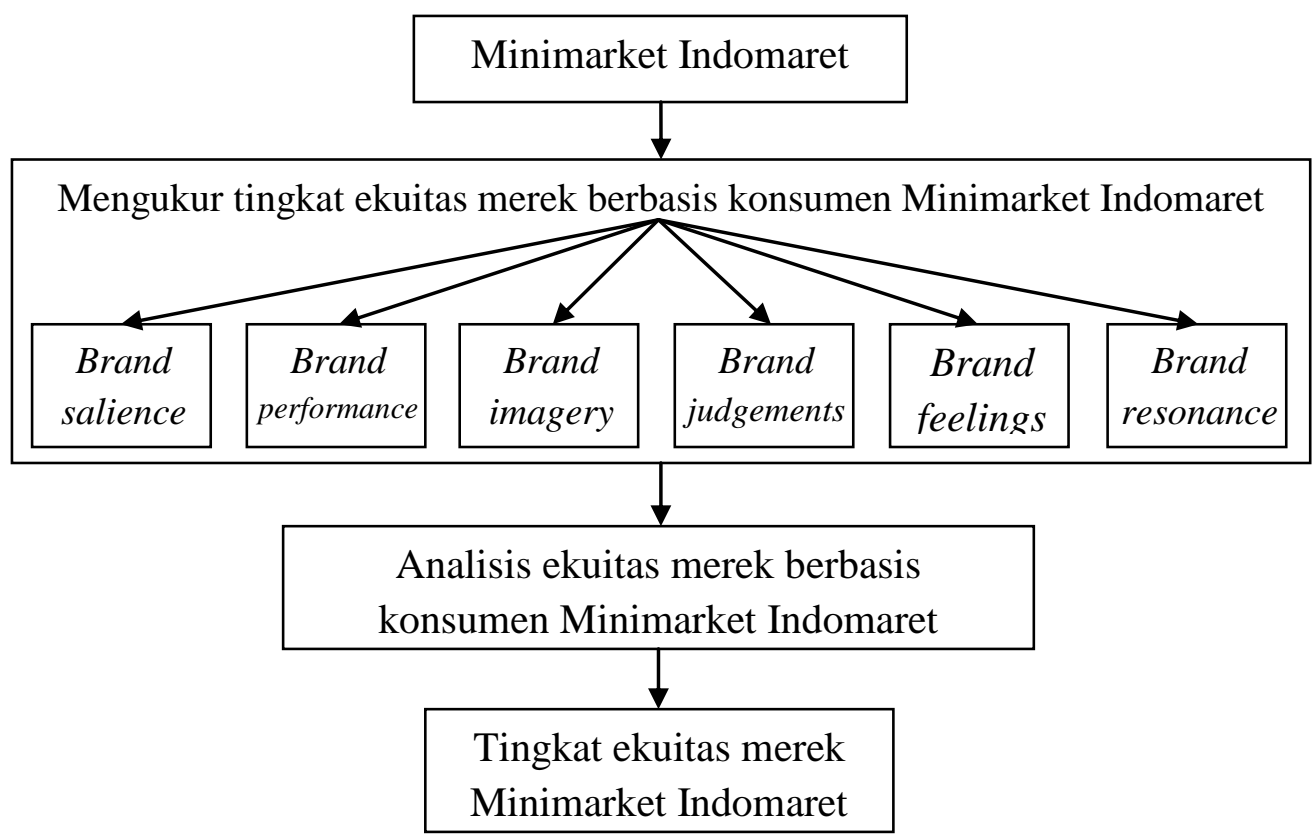

Dari gambar di atas menjelaskan bahwa obyek penelitian adalah Minimarket Indomaret, akan disanalisa ekuitas merek melaluhi indikator: brand salience, brand performance, Brand imagery, Brand judgements, brand feelings dan brand resonance yang akan menghasilkan output informasi tingkat Ekuitas merek berbasis pelanggan pada Indomaret di Salatiga

\section{HIPOTESIS}

Dari rumusan masalah dan tujuan penelitian serta paparan teoritis yang telah dituangkan dalam kerangka pemikiran, maka dapat diambil hipotesis sebagai Berikut:

1. Konsumen mengetahui brand Salience pada ekuitas merek Minimarket Indomaret. 
2. Konsumen mengetahui brand performance pada ekuitas merek Minimarket Indomaret.

3. Konsumen mengetahui brand imagery pada ekuitas merek Minimarket Indomaret.

4. Konsumen mengetahui brand judgements pada ekuitas merek Minimarket Indomaret.

5. Konsumen mengetahui brand feelings pada ekuitas merek Minimarket Indomaret.

\section{E. METODE PENELITIAN}

\section{a. Populasi dan Sampel}

\section{Populasi}

Populasi adalah semua nilai baik perhitungan mauun pegukuran, baik kuantitatif maupun kualitatif, daripada karakteristik tertentu mengenai sekelompok objek yang lengkap dan jelas. (Husaini Usman, 2009:42). Sedangkan menurut Sugiono (2000:72) adalah wilayah generalisasi yang terdiri atas obyek/subyek yang mempunyai kuantitas dan karakteristik tertentu yang ditetapkan oleh peneliti untuk dipelajari dan kemudian ditarik kesimpulannya. Dalam penelitian ini populasi yang dimaksud adalah seluruh pembeli yang berbelanja di Minimarket Indomaret di Salatiga periode bulan Agustus tahun 2015.

\section{Sampel}

Penelitian ini menggunakan teknik non probability sampling, yaitu teknik pengambilan sampel tanpa menggunakan proses random. Anggota populasi dipilih berdasarkan pertimbangan tertentu atau berdasarkan alasan kemudahan saja. Akibatnya anggota populasi yang lain tidak memiliki peluang untuk terpilih.campur tangan periset dalam menentukan anggota sampel sangat besar dalam metode ini (Istijanto,2009:124)

Jumlah anggota sampel yang diambil sering menjadi masalah dalam penelitian. Jumlah anggota sampel tergantung tingkat kepercayaan yang dikehendaki. Tingkat kepercayaan sering tergantung pada sumber dana, waktu, den tenaga peneliti. Makin kecil tingkat kesalahan, maka makin besar jumlah anggota sampel. Ada berbagai referensi yang dipakai untuk menghitung ukuran sampel yang dipakai dalam penelitian, seperti Cohen, Slovin dan lain-lain. Rumus yang satu dengan yang lainnya hanya terdapat sedikit perbedaan dalam ukuran sampel.

Pada umumnya, banyak atau sedikitnya sampel, ditentukan dari jumlah populasi. Akan tetapi, jumlah populasi dari penelitian ini tidak bisa diketahui dengan pasti jumlahnya, sehingga dalam penelitian ini, jumlah populasi tidak digunakan sebagai dasar penghitungan ukuran sampel. 
Malhotra mendefinisikan ukuran sampel dalam bentuk tabel seperti diilustrasikan yang nampak dalam tabel. Dengan mencermati tabel, menurut pengertian Malhotra (2002:351) bahwa untuk pengambilan suatu keputusan, ukuran sampel pada pengujian Ekuitas merek pada Minimarket Indomaret di Salatiga, termasuk ke dalam penelitian tes marketing studies jadi ukuran sampel minimalnya adalah 200 sampel.

Teknik pengambilan sampel yang digunakan dalam penelitian ini adalah teknik purposive sampling. Menurut Sugiyono (2006:78), purposive sampling adalah "tehnik penentuan sampel dengan pertimbangan tertentu". Pertimbangan yang digunakan dalam penelitian ini, diantaranya:

a. Sampel tersebut haruslah merupakan penduduk Kota Salatiga.

b. Sampel tersebut haruslah Konsumen yang pernah berbelanja di Minimarket Indomaret.

c. Sampel tersebut memiliki kemauan untuk membagikan pendapatnya mengenai ekuitas merek pada Minimarket Indomaret.

\section{b. Definisi Operasional}

Definisi Operasional adalah penentuan variabel, sehingga dapat diukur. Definisi operasional menjelaskan cara tertentu yang digunakan oleh peneliti dalam mengoperasionalisasikan variabel. Dengan membaca definisi operasional dalam suatu penelitian, akan diketahui ukuran suatu variabel sehingga diketahui baik buruknya pengukuran tersebut.

Dalam penelitian ini untuk mengukur brand salience, brand performance, brand imagery, brand judgements, brand feelings dan brand resonance, dimana variabel diukur dan dijabarkan menjadi sub variabel dan dari sub variabel tersebut dijabarkan lagi menjadi indikator-indikator yang dapat di ukur.

Untuk memperjelas uraian tersebut diatas akan ditampilkan indikator masing-masing konsep penelitian yang akan diukur dalam penelitian ini sebagai berikut. 
Tabel 1

Definisi Operasional

\begin{tabular}{|c|c|c|}
\hline Dimensi & Definisi Operasional & Sumber \\
\hline $\begin{array}{l}\text { Brand } \\
\text { salience }\end{array}$ & $\begin{array}{l}\text { 1) Mampu mengenal merek } \\
\text { 2) Mampu mengingat merek } \\
\text { 3) Sering memikirkan merek } \\
\text { 4) Merek mempunyai reputasi yang baik }\end{array}$ & $\begin{array}{l}\text { Tjiptono } \\
\text { (2005: 41) }\end{array}$ \\
\hline $\begin{array}{l}\text { Brand } \\
\text { performance }\end{array}$ & $\begin{array}{l}\text { 1) Reliabilitas, durabilitas, dan serviceability } \\
\text { produk } \\
\text { 2) Efektivitas, efisiensi, dan empati layanan } \\
\text { 3) Model dan desain toko } \\
\text { 4) Harga }\end{array}$ & $\begin{array}{l}\text { Tjiptono } \\
\text { (2005: 41) }\end{array}$ \\
\hline $\begin{array}{l}\text { Brand } \\
\text { imagery }\end{array}$ & $\begin{array}{l}\text { 1) Profil pemakai } \\
\text { 2) Situasi pembelian dan pemakaian } \\
\text { 3) Kepribadian dan nilai-nilai. } \\
\text { 4) Sejarah, warisan dan pengalaman. }\end{array}$ & $\begin{array}{l}\text { Tjiptono } \\
\text { (2005: 41) }\end{array}$ \\
\hline $\begin{array}{l}\text { Brand } \\
\text { judgements }\end{array}$ & $\begin{array}{l}\text { 1) Aspek Brand quality } \\
\text { 2) Aspek Brand credibility } \\
\text { 3) Aspek Brand consediration } \\
\text { 4) Aspek Brand superiority }\end{array}$ & $\begin{array}{l}\text { Tjiptono } \\
\text { (2005: 41) }\end{array}$ \\
\hline Brand feelings & $\begin{array}{l}\text { 1) Rasa bersemangat } \\
\text { 2) Rasa nyaman } \\
\text { 3) Rasa bangga } \\
\text { 4) Rasa percaya diri }\end{array}$ & $\begin{array}{l}\text { Tjiptono } \\
\text { (2005: 42) }\end{array}$ \\
\hline $\begin{array}{l}\text { Brand } \\
\text { resonance }\end{array}$ & $\begin{array}{l}\text { 1) Sering berbelanja } \\
\text { 2) Mengutamakan merek } \\
\text { 3) Sering mencari informasi merek } \\
\text { 4) Mempengaruhi orang lain }\end{array}$ & $\begin{array}{l}\text { Tjiptono } \\
\text { (2005: 42) }\end{array}$ \\
\hline
\end{tabular}

\section{c. Metode Analisis Data}

Untuk mempermudah dan mempercepat analisa data serta agar hasil perhitungan yang dihasilkan lebih dapat dipercaya, maka seluruh pengolahan data dalam penelitian ini akan dilakukan dengan menggunakan SPSS. 


\section{Uji Validitas}

Validitas menunjuk sejauh mana suatu alat pengukur itu mampu mengukur apa yang ingin diukur. Yang dimaksud dengan validitas adalah suatu ukuran yang menunjukan tingkat kevalidan atau kesahihan sesuatu instrumen (Arikunto, 2006 : 168-170 ). Hasil penelitian yang valid bila terdapat kesamaan anrata data yang terkumpul dengan data yang sesungguhnya terjadi pada objek yang diteliti (Sugiyono, 2004:109). Dalam hal analisis ini Masrun (Sugiyono, 2004:124) menyatakan teknik korelasi untuk menentukan validitas item ini sampai sekarang merupakan teknik yang paling banyak digunakan.

Cara yang digunakan adalah dengan analisis item (corrected item to total corelation), dimana setiap nilai yang ada pada setiap butir pertanyaan dikorelasikan dengan total nilai seluruh butir pertanyaan suatu variabel, kemudian dibandingkan dengan $r$ tabel. Dalam penelitian ini menggunakan taraf signifikasi 0,05 yang merupakan ukuran standar yang sering digunakan dalam penelitian.Untuk mengetahui $r$ tabel digunakan rumus $\mathrm{df}=\mathrm{n}-2$, dimana $\mathrm{n}$ adalah jumlah sampel dengan degree of freedom sebesar 5\% atau $\alpha / 2$ pada table. Perhitungan dapat dilakukan dengan menggunakan rumus korelasi sebagi berikut:

$$
r_{i(x-1)}=\frac{n \sum i(x-i)-\left(\sum i\right)\left(\sum(x-i)\right)}{\sqrt{\left\{n \sum i-\left(\sum i\right)^{2} \mid n \sum(x-i)^{2}-\left(\sum(x-i)\right)^{2}\right\}}}
$$

$$
\begin{aligned}
& \text { Keterangan : } \\
& \begin{aligned}
i & =\text { Skor item } \\
(x-i) & =\text { Skor total item dikurangiskor item } \\
n & =\text { Banyaknya subjek }
\end{aligned}
\end{aligned}
$$

Jika nilai korelasi ( $\mathrm{r}$ hitung) antara masing-masing indikator terhadap total skor konstruk menunjukan hasil > $\mathrm{r}$ tabelnya maka indikator masing-masing pertanyaan valid dan sebaliknya.

\section{Uji Reliabilitas}

Uji realibilitas adalah suatu instrumen cukup dipercaya untuk digunakan sebagai alat pengumpul data karena instrumen tersebut sudah baik (Arikunto,2006 : 178 ). Untuk melakukan uji reliabilitas dalam penelitian ini menggunakan uji statistik Cronbach $\operatorname{Alpha}(\alpha)$. Secara matematis uji statistik Cronbach Alpha $(\alpha)$ dapat dilakukan dengan menggunakan rumus sebagai berikut :

$$
r_{11}=\left(\frac{k}{(k-1)}\right)\left(1-\frac{\sum \sigma_{b^{2}}}{\sigma^{2} t}\right)
$$

Keterangan :

$$
\begin{aligned}
& \mathrm{r}_{11}=\text { reliabilitas instrumen } \\
& \mathrm{k}=\text { banyaknya butir pertanyaan atau banyaknya soal } \\
& \sum \sigma_{\mathrm{b}^{2}}=\text { jumlah varians butir }
\end{aligned}
$$




$$
\sigma_{\mathrm{t}^{2}}=\text { varians total }
$$

Suatu konstruk atau variabel dikatakan reliabel jika memberikan nilai Alpha >0,60

\section{Analisis Chi Square}

Uji chi - square termasuk salah stu alat uji yang sering digunakan dalam praktek. Dalam bahasan statistik nonparametrik, uji chi - square untuk suatu sampel bisa dipakai untuk menguji apakah data sebuah sampel yang diambil menunjang hipotesis yang menyatakan bahwa populasi asal sampel tersebut mengikuti suatu distribusi yang telah ditetapkan ( Singgih Santoso, 2003 : 400 ). Pengolahan data mengenai dilakukan dengan cara mentabulasikan data yang diperoleh. Untuk menyusun kuesioner mengenai brand salience, brand performance, brand imagery, brand judgments, brand feelings dan brand resonance digunakan skala likert. Penyajian data dalam penelitian ini dipergunakan metode chi square $\left(X^{2}\right)$ adalah teknik statistik yang digunakan untuk menguji hipotesis bila dalam populasi terdiri atas dua atau lebih kelas dan sampelnya besar. Rumus uji chi square:

$$
x^{2}=\frac{\sum(\text { fo }-\mathrm{fh}) 2}{\text { fo }}
$$

$$
\begin{aligned}
X^{2}= & \text { chi kuadrat / chi square } \\
\text { fo }= & \text { Frekuensi yang diperoleh dari sample } \\
\mathrm{fh}= & \text { frekuensi yang diharapkan dalam sample sebagai pencerminan } \\
& \text { frekuensi yang diharapkan dalam populasi } \\
& \text { Derajat kebebasan }(\mathrm{db}) \text { diperoleh dari }(\mathrm{b}-1)(\mathrm{k}-1)
\end{aligned}
$$

Dalam penelitian ini menggunakan chi - square untuk menganalisa data nominal berbentuk frekuensi. Hal ini dimaksudkan untuk mengetahui prilaku konsumen. Ada beberapa hal yang perlu diperhatikan dalam menggunakan Chi-kudarat:

a. Chi - square digunakan untuk menganalisa data yang berbentuk frekuensi.

b. Chi - square tidak dapat digunakan untuk menentukan besar atau kecilnya korelasi dari variabel-variabel yang dianalisa.

c. Chi - square pada dasarnya belum dapat menghasilkan kesimpulan yang memuaskan.

d. Chi - square cocok digunakan untuk data kategorik, data diskrit atau data nominal.

\section{Uji Hipotesis}

Menjelaskan dasar untuk menerima atau menolak hipotesis nol. Unsur yang terkandung yaitu tingkat signifikansi (sig). membandingkan nilai hitung dengan nilai tabel yaitu degrees of freedom $(\mathrm{df})=($ jumlah baris -1$) \times($ jumlah kolom -1$)$ dengan P-value 5\%

Ho diterima $=$ Jika $\chi^{2}$ hitung $<$ dari $\chi^{2}$ Tabel atau sig $>\alpha$ 
Ha diterima $=$ Jika $\chi^{2}$ hitung $>$ dari $\chi^{2}$ Tabel atau sig $<\alpha$

\section{F. ANALISIS DATA DAN PEMBAHASAN}

\section{Uji Validitas}

Uji Validitas dilakukan untuk mengetahui tingkat kevalidan indikator yang digunakan atau indikator sebagai alat ukur variabel. Dalam penelitian ini, uji validitas menggunakan Scale (Corrected Item Total Colleration). Nilai korelasi (r) hasil perhitungan kemudian dikonsultasikan dengan nilai $r$ yang terdapat pada tabel. Jika $r_{\text {hitung }}$ $>\mathrm{r}_{\text {tabel }}$ maka item Pernyataan tersebut adalah valid dan jika $\mathrm{r}_{\text {hitung }}<\mathrm{r}_{\text {tabel }}$ maka Pernyataan tersebut tidak valid dan harus dikeluarkan dari instrument. Nilai $r$ tabel untuk jumlah responden $(N)$ sebanyak 200 dengan df $=198(n-2)$, pada taraf signifikansi $\alpha=5 \%$ adalah 0,139 . Penghitungan validitas yang digunakan dalam penelitian ini menggunakan program SPSS versi 16.0 dan hasilnya dapat dilihat pada tabel dibawah ini:

Tabel 2

Hasil Pengujian Validitas

\begin{tabular}{|c|c|c|c|c|}
\hline No & Indikator & $\mathrm{r}_{\text {hitung }}$ & $r_{\text {tabel }}$ & Keterangan \\
\hline \multirow[t]{5}{*}{1} & Brand Salience & & & \\
\hline & - Pernyataan No. 1 & 0,266 & 0,139 & Valid \\
\hline & - Pernyataan No. 2 & 0,280 & 0,139 & Valid \\
\hline & - Pernyataan No. 3 & 0,598 & 0,139 & Valid \\
\hline & - Pernyataan No. 4 & 0,565 & 0,139 & Valid \\
\hline \multirow[t]{5}{*}{2} & Brand Performance & & & \\
\hline & - Pernyataan No. 1 & 0,410 & 0,139 & Valid \\
\hline & - Pernyataan No. 2 & 0,389 & 0,139 & Valid \\
\hline & - Pernyataan No. 3 & 0,523 & 0,139 & Valid \\
\hline & - Pernyataan No. 4 & 0,614 & 0,139 & Valid \\
\hline \multirow[t]{5}{*}{3} & Brand Imagery & & & \\
\hline & - Pernyataan No. 1 & 0,529 & 0,139 & Valid \\
\hline & - Pernyataan No. 2 & 0,477 & 0,139 & Valid \\
\hline & - Pernyataan No. 3 & 0,684 & 0,139 & Valid \\
\hline & - Pernyataan No. 4 & 0,727 & 0,139 & Valid \\
\hline \multirow[t]{5}{*}{4} & Brand Judgments & & & \\
\hline & - Pernyataan No. 1 & 0,568 & 0,139 & Valid \\
\hline & - Pernyataan No. 2 & 0,607 & 0,139 & Valid \\
\hline & - Pernyataan No. 3 & 0,603 & 0,139 & Valid \\
\hline & - Pernyataan No. 4 & 0,597 & 0,139 & Valid \\
\hline
\end{tabular}

Analisis Ekuitas Merek Berbasis Pelanggan Pada Minimarket Indomaret Di Salatiga 


\begin{tabular}{|c|l|c|c|c|}
\hline No & \multicolumn{1}{|c|}{ Indikator } & $\mathrm{r}_{\text {hitung }}$ & $\mathrm{r}_{\text {tabel }}$ & Keterangan \\
\hline 5 & Brand Feelings & & & \\
\hline & - Pernyataan No. 1 & 0,594 & 0,139 & Valid \\
\hline & - Pernyataan No. 2 & 0,516 & 0,139 & Valid \\
\hline & - Pernyataan No. 3 & 0,582 & 0,139 & Valid \\
\hline 6 & - Pernyataan No. 4 & 0,613 & 0,139 & Valid \\
\hline & Brand Resonance & & & \\
\hline & - Pernyataan No. 1 & 0,653 & 0,139 & Valid \\
\hline & - Pernyataan No. 2 & 0,489 & 0,139 & Valid \\
\hline & - Pernyataan No. 4 3 & 0,517 & 0,139 & Valid \\
\hline
\end{tabular}

Sumber: Data primer yang diolah tahun 2015

Dari hasil pengujian validitas yang ditampilkan pada table diatas menyatakan bahwa hasil dari masing-masing butir Pernyataannya memiliki $r_{\text {hitung }}>r$ tabel yang disyaratkan yaitu 0,139. Dengan demikian semua butir Pernyataan/ indikator dari variabel Brand, harga, kualitas pelayanan dan keputusan pembelian dinyatakan valid. Karena dari hasil korelasi antara hasil jawaban responden pada tiap item Pernyataan/ indikator lebih besar dari $r_{\text {tabel }}$, sehingga Pernyataan dalam kuesioner dapat menjelaskan variabel yang digunakan.

\section{Uji Reliabilitas}

Uji Reliabilitas untuk mengetahui apakah indikator yang digunakan dapat dipercaya atau handal sebagai alat ukur variabel. Apabila nilai cronbach's alpha $(\alpha)$ suatu variabel $>0,60$ maka indikator yang digunakan oleh variabel tersebut reliabel, sedangkan bila nilai cronbach's alpha $(\alpha)$ suatu variabel $<0,60$ maka indikator yang digunakan oleh variabel tersebut tidak reliabel. Penghitungan reliabilitas yang digunakan dalam penelitian ini menggunakan program SPSS versi 16.0 dan hasilnya dapat dilihat pada tabel dibawah ini: 
Tabel 3

Hasil Uji Reliabilitas

\begin{tabular}{|c|l|c|c|c|}
\hline No & \multicolumn{1}{|c|}{ Variabel } & $\begin{array}{c}\text { Cronbach } \\
\text { Alpha }\end{array}$ & $\begin{array}{c}\text { Alpha } \\
\text { Pembanding }\end{array}$ & Keterangan \\
\hline 1 & Brand Salience & 0,891 & 0,6 & Reliabel \\
\hline 2 & Brand Performance & 0,870 & 0,6 & Reliabel \\
\hline 3 & Brand Imagery & 0,849 & 0,6 & Reliabel \\
\hline 4 & Brand Judgments & 0,867 & 0,6 & Reliabel \\
\hline 5 & Brand Feelings & 0,866 & 0,6 & Reliabel \\
\hline 6 & Brand Resonance & 0,869 & 0,6 & Reliabel \\
\hline
\end{tabular}

Sumber: Data primer yang diolah tahun 2015

Pada tabel diatas menunjukkan bahwa nilai cronbach's alpha semua variabel di atas 0,60 sehingga dapat disimpulkan indikator yang digunakan oleh variabel Brand, harga, kualitas pelayanan dan keputusan pembelian dapat dipercaya atau handal untuk digunakan sebagai alat ukur variabel.

\section{Analisis Chi square dan Uji Hipotesis}

Analisis ini digunakan untuk perbedaan antara frekuensi pengamatan dan frekuensi harapan. Dalam penelitian ini, uji validitas menggunakan Nonparametric Test (chi-square). Nilai $\left(\chi^{2}\right)$ hasil perhitungan kemudian dikonsultasikan dengan nilai $\chi^{2}$ yang terdapat pada tabel. Jika $\chi^{2}$ hitung $>\chi^{2}$ tabel maka tersebut menunjukan pelanggan mengetahui item pernyataan. Nilai $\chi^{2}$ tabel untuk jumlah responden $(\mathrm{N})$ sebanyak 200 dengan $\mathrm{df}=199$ (n-1), pada taraf signifikansi $\alpha=5 \%$ adalah 232,912. Penghitungan chi-square digunakan dalam penelitian ini menggunakan program SPSS versi 16.0 dan hasilnya dapat dilihat pada tabel dibawah ini:

\section{a. Brand Salience Minimarket Indomaret}

\section{Tabel 4}

Brand Salience Minimarket Indomaret

\begin{tabular}{|c|l|c|}
\hline NO & \multicolumn{1}{|c|}{ PERNYATAAN } & $\begin{array}{c}\text { PERSENTASE SANGAT } \\
\text { SETUJU DAN SETUJU }\end{array}$ \\
\hline 1 & Mampu mengenal merek & $97,0 \%$ \\
\hline 2 & Mampu mengingat merek & $92,5 \%$ \\
\hline 3 & Sering memikirkan merek & $42,0 \%$ \\
\hline 4 & Merek mempunyai reputasi yang baik & $74,0 \%$ \\
\hline
\end{tabular}

Sumber: Data primer yang diolah tahun 2015 
Dari empat indikator mengenai Brand Salience Minimarket Indomaret di Salatiga, konsumen memiliki tanggapan yang positif. Hal ini membuktikan bahwa Minimarket Indomaret di Salatiga merupakan minimarket yang dikenal oleh masyarakat.

Tabel 5

Hasil Uji Chi square Brand Salience

\begin{tabular}{|c|l|c|c|c|c|}
\hline No & Indikator & $\chi_{\text {hitung }}^{2}$ & $\chi_{\text {tabel }}^{2}$ & Sig & Uji Hipotesis \\
\hline 1 & Brand Salience & 2268,244 & 232,912 & .000 & Ha diterima \\
\hline & - Pernyataan No. 1 & 2238,863 & 232,912 & .000 & \\
\hline & - Pernyataan No. 2 & 2472,308 & 232,912 & .000 & \\
\hline & - Pernyataan No. 3 & 1404,877 & 232,912 & .000 & \\
\hline & - Pernyataan No. 4 & 2539,558 & 232,912 & .000 & \\
\hline
\end{tabular}

Sumber: Data primer yang diolah tahun 2015

Berdasarkan tabel diatas karena chi square hitung 2268,244 > chi square tabel 232,912 dan probabilitasnya $0,000<0,05$ maka Ha diterima sehingga konsumen mengetahui brand Salience pada ekuitas merek Minimarket Indomaret di Salatiga, yang berarti konsumen mengetahui setiap indikator dalam ekuitas merek pada Minimarket Indomaret di Salatiga.

\section{b. Brand Performance Minimarket Indomaret}

\section{Tabel 6}

Brand Performance Minimarket Indomaret

\begin{tabular}{|c|l|c|}
\hline NO & \multicolumn{1}{|c|}{ PERNYATAAN } & $\begin{array}{c}\text { PERSENTASE SANGAT } \\
\text { SETUJU DAN SETUJU }\end{array}$ \\
\hline 1 & $\begin{array}{l}\text { Reliabilitas, durabilitas, dan } \\
\text { serviceability produk }\end{array}$ & $92,0 \%$ \\
\hline 2 & $\begin{array}{l}\text { Efektivitas, efisiensi, dan empati } \\
\text { layanan }\end{array}$ & $73,5 \%$ \\
\hline 3 & Model dan Desain & $71,0 \%$ \\
\hline 4 & Harga terjangkau & $56,5 \%$ \\
\hline
\end{tabular}

Sumber: Data primer yang diolah tahun 2015

Dari empat indikator mengenai Brand Performance Minimarket Indomaret, konsumen memiliki tanggapan yang positif. Hal ini membuktikan bahwa Minimarket Indomaret di Salatiga mempunyai performa yang bagus. 
Tabel 7

Hasil Uji Chi square Brand Performance

\begin{tabular}{|c|c|c|c|c|c|}
\hline No & Indikator & $\chi_{\text {hitung }}^{2}$ & $\chi_{\text {tabel }}$ & Sig & Uji Hipotesis \\
\hline 2 & Brand Performance & 1515,336 & 232,912 & .000 & Ha diterima \\
\hline & - Pernyataan No. 1 & 2135,952 & 232,912 & .000 & \\
\hline & - Pernyataan No. 2 & 1525,873 & 232,912 & .000 & \\
\hline & - Pernyataan No. 3 & 1882,675 & 232,912 & .000 & \\
\hline & - Pernyataan No. 4 & 1728,497 & 232,912 & .000 & \\
\hline
\end{tabular}

Sumber: Data primer yang diolah tahun 2015

Berdasarkan tabel diatas karena chi square hitung 1515,336 > chi square tabel 232,912 dan probabilitasnya $0,000<0,05$ maka Ha dterima sehingga konsumen mengetahui brand performance pada ekuitas merek Minimarket Indomaret di Salatiga, yang berarti konsumen mengetahui setiap indikator dalam ekuitas merek pada Minimarket Indomaret di Salatiga.

\section{c. Brand Imagery Minimarket Indomaret}

\section{Tabel 8}

Brand Imagery Minimarket Indomaret

\begin{tabular}{|c|l|c|}
\hline NO & \multicolumn{1}{|c|}{ PERNYATAAN } & $\begin{array}{c}\text { PERSENTASE SANGAT } \\
\text { SETUJU DAN SETUJU }\end{array}$ \\
\hline 1 & Profil pemakai & $74,0 \%$ \\
\hline 2 & Situasi pembelian dan pemakaian & $88,5 \%$ \\
\hline 3 & Kepribadian dan nilai-nilai. & $45,0 \%$ \\
\hline 4 & Sejarah, warisan dan pengalaman. & $38,5 \%$ \\
\hline
\end{tabular}

Sumber: Data primer yang diolah tahun 2015

Dari empat indikator Brand Imagery Minimarket Indomaret di Salatiga konsumen memiliki tanggapan yang positif pada indikator profil pemakai dan situasi pembelian. Tetapi untuk indikator kepribadian nilai nilai dan sejarah warisan kurang ditanggapi dengan baik oleh konsumen. Sebaiknya Minimarket Indomaret di Salatiga kembali mengeluarkan iklannya yang baru agar mampu menarik minat konsumen untuk berbelanja di minimarket Indomaret. 
Tabel 9

Hasil Uji Chi square Brand Imagery

\begin{tabular}{|c|l|c|c|c|c|}
\hline No & Indikator & $\chi^{2}$ hitung & $\chi_{\text {tabel }}^{2}$ & Sig & Uji Hipotesis \\
\hline 3 & Brand Imagery & 1918,372 & 232,912 & .000 & Ha diterima \\
\hline & - Pernyataan No. 1 & 2076,325 & 232,912 & .000 & \\
\hline & - Pernyataan No. 2 & 2750,178 & 232,912 & .000 & \\
\hline & - Pernyataan No. 3 & 1295,428 & 232,912 & .000 & \\
\hline & - Pernyataan No. 4 & 1263,709 & 232,912 & .000 & \\
\hline
\end{tabular}

Sumber: Data primer yang diolah tahun 2015

Berdasarkan tabel diatas karena chi square hitung 1918,372 > chi square tabel 232,912 dan probabilitasnya $0,000<0,05$ maka Ha dterima sehingga konsumen mengetahui brand imagery pada ekuitas merek Minimarket Indomaret di Salatiga, yang berarti konsumen mengetahui setiap indikator dalam ekuitas merek pada Minimarket Indomaret di Salatiga.

\section{d. Brand Judgments Minimarket Indomaret}

Tabel 10

Brand Judgments Minimarket Indomaret

\begin{tabular}{|c|l|c|}
\hline NO & \multicolumn{1}{|c|}{ PERNYATAAN } & $\begin{array}{c}\text { PERSENTASE SANGAT } \\
\text { SETUJU DAN SETUJU }\end{array}$ \\
\hline 1 & Aspek Brand quality & $84,5 \%$ \\
\hline 2 & Aspek Brand credibility & $81,5 \%$ \\
\hline 3 & Aspek Brand consediration & $73,5 \%$ \\
\hline 4 & Aspek Brand superiority & $57,5 \%$ \\
\hline
\end{tabular}

Sumber: Data primer yang diolah tahun 2015

Dari empat indikator Brand Judgments Minimarket Indomaret di Salatiga, konsumen memiliki tanggapan yang positif. Tetapi untuk indikator Minimarket Indomaret cukup menonjol (Brand superiority) dibandingkan minimarket lain sedikit lemah, oleh karena itu Minimarket Indomaret harus mengusahakan agar dapat bersaing mereknya dengan minimarket lain, sehingga cukup mononjol mereknya diantara minimarket lain. Dapat dilakukan dengan cara meningkatkan promosi, membuat inovasi-inovasi baru terhadap Minimarket Indomaret di Salatiga sehingga ada ciri khasnya sendiri.

Tabel 11

Hasil Uji Chi square Brand Judgments

\begin{tabular}{|c|l|c|c|c|c|}
\hline No & Indikator & $\chi_{\text {hitung }}^{2}$ & $\chi_{\text {tabel }}^{2}$ & sig & Uji Hipotesis \\
\hline 4 & Brand Judgments & 5245,927 & 232,912 & .000 & Ha diterima \\
\hline & - Pernyataan No. 1 & 2803,928 & 232,912 & .000 & \\
\hline
\end{tabular}




\begin{tabular}{|c|c|c|c|c|c|}
\hline No & Indikator & $\chi_{\text {hitung }}^{2}$ & $\chi_{\text {tabel }}^{2}$ & sig & Uji Hipotesis \\
\hline & - Pernyataan No. 2 & 3992,106 & 232,912 & .000 & \\
\hline & - Pernyataan No. 3 & 3021,675 & 232,912 & .000 & \\
\hline & - Pernyataan No. 4 & 1858,051 & 232,912 & .000 & \\
\hline
\end{tabular}

Sumber: Data primer yang diolah tahun 2015

Berdasarkan tabel diatas karena chi square hitung 5245,927 > chi square tabel 232,912 dan probabilitasnya $0,000<0,05$ maka Ha dterima sehingga konsumen mengetahui brand judgements pada ekuitas merek Minimarket Indomaret di Salatiga, yang berarti konsumen mengetahui setiap indikator dalam ekuitas merek pada Minimarket Indomaret di Salatiga.

\section{e. Brand Feelings Minimarket Indomaret}

Tabel 12

Brand Feelings Minimarket Indomaret

\begin{tabular}{|c|l|c|}
\hline NO & \multicolumn{1}{|c|}{ PERNYATAAN } & $\begin{array}{c}\text { PERSENTASE SANGAT } \\
\text { SETUJU DAN SETUJU }\end{array}$ \\
\hline 1 & Rasa bersemangat & $74,5 \%$ \\
\hline 2 & Rasa nyaman & $80,0 \%$ \\
\hline 3 & Rasa bangga & $31,5 \%$ \\
\hline 4 & Rasa percaya diri & $29,5 \%$ \\
\hline
\end{tabular}

Sumber: Data primer yang diolah tahun 2015

Dari empat indikator Brand Feelingss Minimarket Indomaret di Salatiga, konsumen memiliki tanggapan yang positif pada indikator rasa bersemangat dan rasa nyaman. Tetapi untuk indikator rasa bangga dan rasa percaya diri lain kurang ditanggapi dengan baik oleh konsumen, oleh karena itu Minimarket Indomaret di Salatiga harus mengusahakan meningkatkan nilai prestise (gengsi) agar dapat meningkatkan rasa bangga dan rasa percaya diri konsumen

Tabel 13

Hasil Uji Chi square Brand Feelings

\begin{tabular}{|c|l|c|c|c|c|}
\hline No & Indikator & $\chi_{\text {hitung }}^{2}$ & $\chi_{\text {tabel }}^{2}$ & sig & Uji Hipotesis \\
\hline 5 & Brand Feelings & 3368,959 & 232,912 & .000 & Ha diterima \\
\hline & - Pernyataan No. 1 & 3356,575 & 232,912 & .000 & \\
\hline & - Pernyataan No. 2 & 3749,134 & 232,912 & .000 & \\
\hline
\end{tabular}




\begin{tabular}{|c|c|c|c|c|c|}
\hline No & Indikator & $\chi_{\text {hitung }}^{2}$ & $\chi_{\text {tabel }}^{2}$ & sig & Uji Hipotesis \\
\hline & - Pernyataan No. 3 & 1932,620 & 232,912 & .000 & \\
\hline & - Pernyataan No. 4 & 1316,414 & 232,912 & .000 & \\
\hline
\end{tabular}

Sumber: Data primer yang diolah tahun 2015

Berdasarkan tabel diatas karena chi square hitung 3368,959 > chi square tabel 232,912 dan probabilitasnya $0,000<0,05$ maka Ha dterima sehingga konsumen mengetahui brand feelings pada ekuitas merek Minimarket Indomaret di Salatiga, yang berarti konsumen mengetahui setiap indikator dalam ekuitas merek pada Minimarket Indomaret di Salatiga.

\section{f. Brand Resonance Minimarket Indomaret}

Tabel 14

Brand Resonance Minimarket Indomaret

\begin{tabular}{|c|l|c|}
\hline NO & \multicolumn{1}{|c|}{ PERNYATAAN } & $\begin{array}{c}\text { PERSENTASE SANGAT } \\
\text { SETUJU DAN SETUJU }\end{array}$ \\
\hline 1 & Sering berbelanja & $50,0 \%$ \\
\hline 2 & Mengutamakan merek & $39,5 \%$ \\
\hline 3 & Sering mencari informasi merek & $46,0 \%$ \\
\hline 4 & Mempengaruhi orang lain & $36,0 \%$ \\
\hline
\end{tabular}

Sumber: Data primer yang diolah tahun 2015

Dari empat indikator Brand Resonance Minimarket Indomaret di Salatiga, konsumen memiliki tanggapan yang kurang baik. Rendahnya tingkat Brand Resonance dari minimaket Indomaret di Salatiga, karena tidak semua responden berbelanja di Minimarket Indomaret di Salatiga, dan kemungkinan sebagian besar hanya pernah mencoba saja, selain itu konsumen cenderung untuk membandingkan saja dengan minimarket lain.

Tabel 15

Hasil Uji Chi square Brand Resonance

\begin{tabular}{|c|c|c|c|c|c|}
\hline No & Indikator & $\chi_{\text {hitung }}^{2}$ & $\chi_{\text {tabel }}^{2}$ & sig & Uji Hipotesis \\
\hline 6 & Brand Resonance & 1660,247 & 232,912 & .000 & Ha diterima \\
\hline & - Pernyataan No. 1 & 1088,914 & 232,912 & .000 & \\
\hline & - Pernyataan No. 2 & 1592,747 & 232,912 & .000 & \\
\hline & - Pernyataan No. 3 & 1345,949 & 232,912 & .000 & \\
\hline & - Pernyataan No. 4 & 1341,671 & 232,912 & .000 & \\
\hline
\end{tabular}


Berdasarkan tabel diatas karena chi square hitung 1660,247 > chi square tabel 232,912 dan probabilitasnya $0,000<0,05$ maka Ha diterima sehingga konsumen mengetahui brand resonance pada ekuitas merek Minimarket Indomaret di Salatiga, yang berarti konsumen mengetahui setiap indikator dalam ekuitas merek pada Minimarket Indomaret di Salatiga.

Secara keseluruhan ekuitas merek dari Minimarket Indomaret di Salatiga sudah ditanggapi positif oleh konsumen, ini dapat dilihat bahwa responden sudah mengetahui, mempelajari, melihat, merasakan, dan memiliki pengalaman beberapa waktu dengan Minimarket Indomaret, sehingga pihak perusahaan sudah memberikan kewajiban dan aset-aset yang dimiliki oleh sebuah merek yang dapat menambah nilai dari Minimarket Indomaret di Salatiga.

\section{G. KESIMPULAN}

Berdasarkan uraian dan pembahasan yang telah dikemukakan pada bab sebelumnya, maka ditarik beberapa kesimpulan sebagai berikut:

1. Ekuitas merek berbasis pelanggan yang terdiri dari brand salience, brand performance, brand imagery, brand judgments, brand feelings, dan brand resonance dikatakan berpengaruh positif pada suatu merek apabila pelanggan bereaksi secara lebih positif terhadap sebuah produk dan cara produk tersebut dipasarkan manakala mereknya diidentifikasi, dibandingkan bila nama mereknya tidak teridentifikasi, serta pelanggan mempunyai tingkat awareness dan familiaritas tinggi terhadap sebuah merek dan memiliki asosiasi merek yang kuat positif dan unik dalam memorinya.

2. Brand salience Minimarket Indomaret memiliki tingkat awareness yang cukup tinggi, karena semua pelanggan sudah mengetahui nama minimarket Indomaret. dilihat dari hasil pengujian chi-square dan semuanya menerima hasil uji chisquare salience 2268,244 , dengan nilai $\chi_{\text {tabel }}^{2} 232,912$ maka ha diterima.

3. Pelanggan mengetahui brand performance dari minimarket Indomaret dan berpengaruh positif terhadapnya. dilihat dari hasil pengujian chi-square performance 1515,336 , dengan nilai $\chi^{2}$ tabel 232,912 maka Ha diterima.

4. Pelanggan mengetahui brand imagery dari minimarket Indomaret memiliki tanggapan yang positif pada indikator profil pemakai dan situasi pembelian. Tetapi untuk indikator kepribadian nilai nilai dan sejarah warisan kurang ditanggapi dengan baik oleh konsumen. Dilihat dari hasil pengujian chi-square imagery 1918,372 dengan nilai $\chi_{\text {tabel }}^{2} 232,912$ maka Ha diterima.

5. Pelanggan mengetahui brand judgments dari minimarket Indomaret dan berpengaruh positif terhadapnya, yang didukung oleh indikator-indikator dari kualitas, merek yang bereputasi bagus, memperdulikan kepentingan para 
pelanggan. Tetapi untuk indikator merek Minimarket Indomaret cukup menonjol dibandingkan minimarket lain ditanggapi kurang baik oleh konsumen. Dilihat dari hasil pengujian chi-square feelings 3368,959 dengan nilai $\chi_{\text {tabel }}^{2} 232,912$ maka Ha diterima.

6. Pelanggan mengetahui brand feelings dari minimarket Indomaret konsumen memiliki tanggapan yang positif pada indikator rasa bersemangat dan rasa nyaman. Tetapi untuk indikator rasa bangga dan rasa percaya diri lain kurang ditanggapi dengan baik oleh konsumen. dilihat dari hasil pengujian chi-square resonance-nya 1660,247 dengan nilai $\chi^{2}$ tabel 232,912 maka Ha diterima.

7. Pelanggan mengetahui brand resonance dari minimarket Indomaret dan berpengaruh tidak baik terhadapnya. Dilihat dari hasil pengujian chi- square dan semuanya menerima Ha.

8. Secara garis besar ekuitas merek dari minimarket Indomaret sudah ditanggapi positif oleh pelanggan, hal ini dilihat dari semua pelanggan yang mengatahui merek Minimarket Indomaret, memiliki pengalaman dengannya, dan memiliki asosiasi yang kuat dalam memori setiap pelanggan.

\section{H. SARAN}

Berdasarkan penelitian dan analisa yang telah dilakukan, walaupun ekuitas merek dari Minimarket Indomaret sudah ditanggapi positif oleh pelanggan tetapi ada beberapa hal yang perlu diperhatikan oleh pihak perusahaan :

1. Perusahaan telah memenuhi tingkat awareness yang cukup tinggi. Hal ini hendaknya dijadikan modal untuk mengembangkan bisnis. Karena nama besar member kemudahan untuk memenangkan pasar.

2. Perusahaan sebaiknya melakukan inovasi atau pengembangan display maupun pelayanan minimarket Indomaret seperti kemudahan transaksi dan promosi. Selain itu perusahaan sebaiknya meningkatkan performance dari minimarket Indomaret dilihat dari fasilitas dan sarana pendukung, karena bila dibandingkan dengan minimarket pesaingnya masih ada beberapa kekuranga misalnya fasilitas bangku didepan toko dan penyeduh kopi maupun mi instan.

3. Minimarket Indomaret Perlu meningkatkan kepribadian sesuai dengan keinginan konsumen agar mampu membuat konsumen terbasa turum menurun untuk berbelanja di Minimarket Indomaret

4. Tingkat superioritas Minimarket Indomaret sedikit demi sidikit telah tergerus oleh kompetitor lain dengan segala inovasi, maka perusahan perlu memenuhi tantangan tersebu agar tidak tersisihkan. terutama untuk minimarket Alfamart yang secara konsiten terus menggeser kedudukan minimarket Indomaret secara keseluruhan 
5. Konsumen telah merasakan kenyamanan dan keamanan dalam berbelanja di minimarket indomaret namun belum mempunyai nilai positif terhadap kebanggan dan rasa percaya diri. Maka dari itu perusahaan sebaiknya memberikan nilai pertisius yang tinggi guna untuk meningkatkan gengsi berbelanja di Minimarket Indomartet

6. Perusahaan sebaiknya melakuakan riset langsung kepada pelanggan minimarket Indomaret, sehingga mengetahui apa keinginan dari pelanggan, serta dapat mengetahui penilaian yang lebih akurat dari pelanggan dan dapat berpengaruh pada tingkat loyalitas dari pelanggan minimarket Indomaret.

\section{DAFTAR PUSTAKA}

Andi m. Shadat. 2009. Brand belief. Strategi membangun merek berbasis keyakinan. Jakarta: Salemba Empat

Arikunto s. 2006. Prosedur Penelitian Suatu Pendekatan Praktik. Ed revisi vi. Jakarta : PT. Rineka Cipta.

Armstrong dan Kotler 2003. Dasar-dasar pemasaran. Jilid 1. Edisi kesembilan. Jakarta : PT. Indeks Gramedia.

Buchari alma. 2009. Manajemen pemasaran dan pemasaran jasa. Bandung : CV. Alvabeta

Djaali.2008.Psikologi Pendidikan. Jakarta : PT.Bumi Aksara

Durianto,Sugiarto dan Tony Sitinjak. 2001. Strategi Menaklukkan Pasar Melalui Riset Ekuitas Dan Perilaku Merek. Jakarta PT. Gramedia Pustaka Utama.

Fandy Tjiptono. 2005. Pemasaran jasa. Malang: Bayumedia Publising. 2007. Strategi pemasaran. Edisi ke dua. Yogyakarta : Andi.

Freddy rangkuti. 2002. The power of brands. Teknik mengelola brand equity dan strategi pengembangan merek. Jakarta: Gramedia Pustaka

Husaini usman. 2008. Manajemen, Teori, Praktek dan riset pendidikan. Jakarta : Bumi aksara.

Indriantoro. Dan Supomo. 2002. Metodologi Penelitian Bisnis Untuk Akuntansi Dan Manajemen,Edisi Pertama. Yogyakarta: BPFE-Yogyakarta. 
Istijanto. 2009. Aplikasi praktis riset pemasaran : cara praktis meneliti konsumen dan pesaing. Jakarta : PT Gramedia Pustaka Utama

Kotler Philip dan Amstrong. 2001. Prinsip-prinsip manajemen. Jilid 1 edisi kedelapan. Alih bahasa oleh damos sihombing. Mba. Jakarta : Erlangga.

Kotler. Philip, 2000. Manajemen pemasaran. Jakarta : PT. Prenhallindo. , 2008. Manajemen Pemasaran, Edisi Milenium diterjemahkan Benyamin Molan, PT. Prenhallindo, Jakarta

Malhotra. Naresh k. 2004. Marketing research : an applied orientation. Pearson education. Inc.. Fifth edition. New Jersey. USA

Saladin. Djaslim dan Oesman. Yevis marty. 2002. Perilaku konsumen dan pemasaran strategik. Jakarta: Balai Pustaka

Setiadi. Nugroho j. 2003. Perilaku konsumen. Jakarta : Kencana.

Santoso, Singgih. 2003. Mengatasi berbagai Masalah Statistik dengan SPSS Versi 11.5. Jakarta: PT Elex Media Komputindo

Sugiyono. 2000. Metodelogi Penelitian Bisnis. Bandung: CV. Alfabeta . 2008. Metode Penelitian Kunatitatif Kualitatif Dan R\&D. Bandung: Alfabeta .2012. Memahami penelitian kualitatif. Bandung: Alfabeta

Sukmadinata . 2006. Metode penelitian pendidikan. Bandung: Remaja rosdakarya.

Indomaret, "Sejarah Dan Visi” (diakses tanggal 16 April 2015).

[http://indomaret.co.id/korporat/sejarah-dan-visi.html]

Ryzal Phahlevi dan Muh. Parsta Nur Ikhsan. "Tugas Survey Konsep E-Bisnis” (diakses tanggal 16 April 2015).

[http://rizal-levy.blogspot.co.id/2014/06/tugas-survey-konsep-e-bisnis.html]

Septian Deny. “765 Ribu gerai menjamur di Indonesia” (diakses tanggal 16 April 2015). [http://liputan6.com/bisnis/read/814452/765-ribu-gerai-ritel-menjamurdiindonesia]

Winda Larasati, "Profil, Sejarah serta Modal Perusahaan INDOMARET” (diakses tanggal 16 April 2015).

[http://windaalarasati.blogspot.co.id/2014/11/profil-sejarah-serta-modalperusahaan.html] 